\title{
Inattentive Students Errors in Mathematics: Alarming Repetition
}

\author{
Heba Bakr Khoshaim \\ Prince Sultan University \\ Riyadh, Kingdom of Saudi Arabia
}

\begin{abstract}
In mathematics classrooms, errors in students' responses are expected. Such errors are repeatable and predictable. In many cases, the reasons behind such errors might be a lack of comprehension, or inaccuracy in the employed algorithm or even the wrong implementation of algebraic rules. However, errors could occur because of a lack of attention. Students in many cases are not mindful during the process of writing to their responses. Addressing students' errors in mathematics is not a new topic in mathematics education research. Previous studies looked at the influence of errors on students and teachers and their reactions to such errors. Moreover, few studies analysed the type of errors in mathematics classrooms (Guse, 2017). This study aims to investigate the most common inattentive errors occurred in students' responses. The sample was chosen from one private university in Riyadh, the capital city of Saudi Arabia. Students' responses in two calculus classes during the two semesters of academic year 2017-2018 were considered. The researcher analysed 250 students' written mathematical assessments. In addition, 30 photographs of students' work on classrooms' whiteboards were explored. From the analyses, it appeared that missing a symbol (such as the equal sign) or a notation (such as $\frac{d y}{d x}$ ) were the most common inattentive errors whether in classrooms or in exams. The misuse of the equal sign and other symbols come next in repetition. The miss-order of operations appeared to be the error that most likely leads to an inaccurate result and might totally change the flow of the task.
\end{abstract}

Keywords: Mathematical errors; writing in mathematics classrooms; mathematical language; students' responses.

\section{Introduction}

When we teach mathematics, we expect students to be able to communicate about mathematics and demonstrate their understanding of mathematical concepts either verbally or in writing (Powell \& Hebert, 2016). Students use mathematical symbols, notations, terms, definitions, and theorems to apply certain procedures and algorithms with an aim to reach a solution to 
mathematical tasks. Then, teachers assess students' responses to identify students' misconceptions. One of the essential ways to communicate between teachers and students is through their responses (Dündar, 2016). As such, the quality of students' responses (or writing) should be given full attention from both teachers and students in evaluating the students' level of comprehension and fluency in using mathematical concepts.

When responding, students quite often commit some errors. In fact, "students of any age, any country, any era, irrespective of their performance in mathematics, have experienced getting mathematics wrong" (Gagatsis \& Kyriakides, 2000, p. 24). Addressing students' errors in mathematics is not a new topic in mathematics education. Mathematics education researchers have examined the type of errors that occur in students' responses (Guse, 2017; Naidoo \& Naidoo, 2007; Porter \& Masingila, 1995). They found that most of the time the reasons behind the errors or mistakes are a lack of comprehension of the concepts, misunderstanding of the mathematical procedures, or misinterpretation of the problem (Veloo, Krishnasamy, \& Wan Abdullah, 2015). However, the error in students' responses could be "arbitrary" due to the "lack of loyalty to the given" (Naidoo \& Naidoo, 2007, p. 197) or the inaccurate use of the mathematics language (Guse, 2017; Porter \& Masingila, 1995). In many cases the inaccurate use of mathematical terms or symbols occurs because of a lack of attention (Guse, 2017), instead of a lack of understanding.

People use writing to communicate ideas. In that, it is not negotiable that the inaccurate implementation of vocabularies and phrases when writing could cause severe damage to the meaning of sentences. In mathematics classes, terms, symbols and notations are used in place of everyday vocabularies. Using the same argument, the inaccurate use of symbols or notations severely damages the meaning of the mathematical expressions. Unfortunately, the importance of accurate writing in mathematics classrooms has not been given much attention (Guse, 2017). Students focus on the procedure, with limited attention to the details of their responses. Moreover, in many cases, such mistakes are overlooked or disregarded by the teacher, especially when it is clear that the reason behind such mistakes is a lack of focus instead of lack of comprehension and especially when such mistakes do not affect the final answer.

\section{The problem}

Errors in students' responses in mathematical classrooms are repeatable. Meaning, teachers usually observe the same mistakes occurring by different students in different classes. This is because the causes of confusion are in many cases the same. Eventually, teachers can anticipate the errors. For example, if we know that a student in middle school responded inaccurately to $4 \times 4$, then we would guess that the student said the answer is 8 (example given in Gagatsis \& Kyriakides, 2000). We would also guess that probably the student knew what is $4 \times 4$; however, the student was in a hurry to answer with limited attention to the operation itself. In fact, as a teacher of mathematics, I quite often caution students not to commit mistakes that has occurred with previous classes. 
However, despite that caution, many students will still commit the exact mistake. For example, I always remind students who are learning about Exponential Functions that this family of functions should not be confused with the family of Power Functions. However, in calculus classes, quite often I observe the following mistake:

$$
\int 2^{x} d x=\frac{2^{x+1}}{x+1}+c ! !
$$

In many cases, confusion, disturbance, and a lack of attention are the reasons behind inattentive errors. The problem is that the frequency of such errors is really alarming. Some of these errors are harmless, but others are destructive to the meaning of the expression or even the solution. Moreover, such errors might be disregarded or tolerated by teachers. If a student was able to perform the procedure or apply the rule and the answer is (more or less) accurate, then teachers in many cases look past the bad writing. Teachers give attention to the correct algorithms, the accurate procedure and even the exact answers and tolerate the inaccuracy in writing if they believe that such inaccuracy is irrelevant to students' comprehension. This is will lead to the reoccurrence of such errors. Guidance in mathematics writing is essential to learning mathematics (Lee, 2010). In fact, we believe that the continuous careless practice of mathematical notations or symbols lead to incorrect writing habits in classrooms, which will lead to bad writing even in formal settings like exams. More importantly, such practice could severely affect the intended meaning and the proposed solution.

\section{Goal of the Study}

This research addresses "bad" writing in mathematics classrooms. Guse (2017) argued that as much as there is a push to use writing as a learning tool in mathematics classrooms, common mistakes in mathematics writing have not been given much attention. Hence, the aim of the study is to analyze students' responses with regard to careless writing and report on the most common errors and the most destructive ones. The following research questions are addressed:

\section{Research questions:}

1. What is the most common inattentive error occurred by students?

2. What kind of errors that are the most destructive to the task?

It is important to mention here that this study will not focus on student's errors that reflect lack of understanding but rather those that reflect lack of attention. In simple words, this paper addresses mathematical errors where a student was able to perform the required procedure or apply the needed rule and the answer is (more or less) accurate, but there was an inaccurate use of the mathematics language in the response. 


\section{Related Work}

\section{Writing as a learning tool}

People communicate through languages. It is widely agreed upon that there are four skills to the mastering of any language: Speaking, listening, reading and writing. Indeed, writing is a vital form of communication among people. In recent years, writing in classrooms has been supported as a powerful learning tool. This is applicable in all classes including mathematics (Porter \& Masingila, 1995; Urquhart, 2009). The National Council of Teachers of Mathematics (2000) stressed on the importance of writing in mathematics classes. The ability to respond, reflect, explain, and argue in-writing about a solution reflects deep understanding of mathematical concepts. Students should be able to communicate their knowledge through writing (McCormick, 2010). On the other hand, Usiskin (2012) stated "mathematics is both a written language and a spoken language...... Familiarity with this language is a precursor to all understanding" (p. 4). In other words, being able to use the mathematics language accurately reflects understanding. However, still mathematics teachers are accused of ignoring the power of writing when teaching mathematics (Freeman, Higgins, \& Horney, 2016).

\section{History of the use of symbols}

Mathematical concepts are the foundation to address and solve problems in other subjects, such as physics and engineering (Veloo et al., 2015). Natural phenomena are explained by mathematical theories. To do so, students, first, need to translate the natural phenomena to the abstract symbolic world of mathematics. In that, students use mathematics terms, symbols, and notations instead of everyday vocabularies. This is what Lo 'pez-Gay, Sa 'ez' and Torregrosa, (2015) called the "mathematization process" (p. 592). Here, students work with a different language, the mathematics language.

Experiences with the mathematics language begins in early ages. First, pictures of tangible elements along with the basic mathematics symbols $(=)$ and $(-/+)$ are used to explain basic concepts of algebra to young children (see Figure 1). However, very quickly we introduce students to other symbols (Figure 2) and in no time, we take students to the fantastic symbolic world of mathematics where the use of other vocabularies is, in fact, limited (Figure 3) ${ }^{1}$. In secondary math classes, we substitute even basic transition words with mathematics terms or notations. Instead of (for all) we write $(\forall)$, instead of (then/hence) we use $(\Longrightarrow)$, and the list goes on.

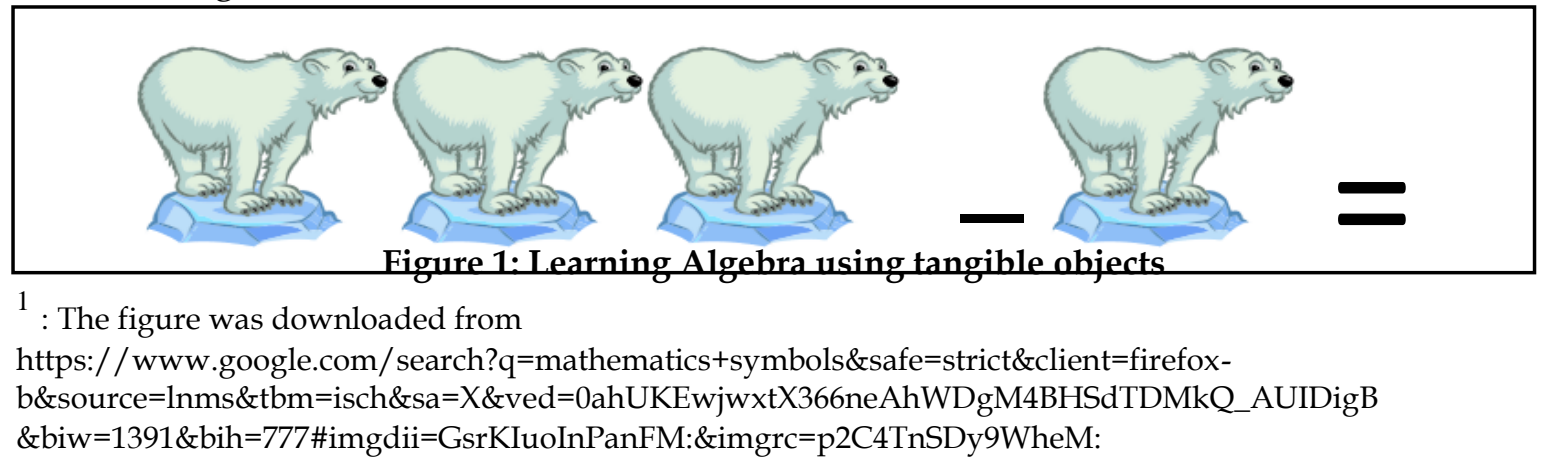




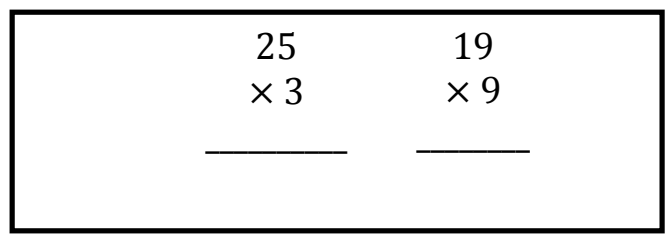

Figure 2: Using symbols in mathematics

Reading, speaking and writing are all important when using the mathematics language. Lee (2010) argued that reading out what you have written loudly can help improve writing in mathematics. The author also suggested to read more in mathematics in order to be able to write in a professional way. Moreover, Vincent, Bardini, Pierce, \& Pearn (2015) stressed that it is essential for students to speak the accurate symbol. The authors stated that "teaching students to read aloud symbolic mathematical statements is an important part of developing their symbolic, and hence, mathematical literacy" (p. 38). The ability to pronounce mathematics aloud accurately will support and enforce the ability to write accurate mathematical expressions. For example, when reading $(-3)$, it is very common to find a student confusing (minus 3) with (negative 3).

Chang, Cromley, and Tran, (2016) stated that the use of mathematical symbols, and signs is essential to be able to communicate the abstract concepts of mathematics. However, working with the mathematics language, just as any other, needs guidance, patience, and time. Practicing the language through writing can support the accurate use of the language (McCormick, 2010). On the other hand, careless writing leads to unfortunate and unavoidable errors. Unfortunately, as much as teachers concentrate on teaching students to be able to choose the correct algorithm, for instance, as much as they discount teaching students to be mindful when using mathematical terms and symbols (Guse, 2017).

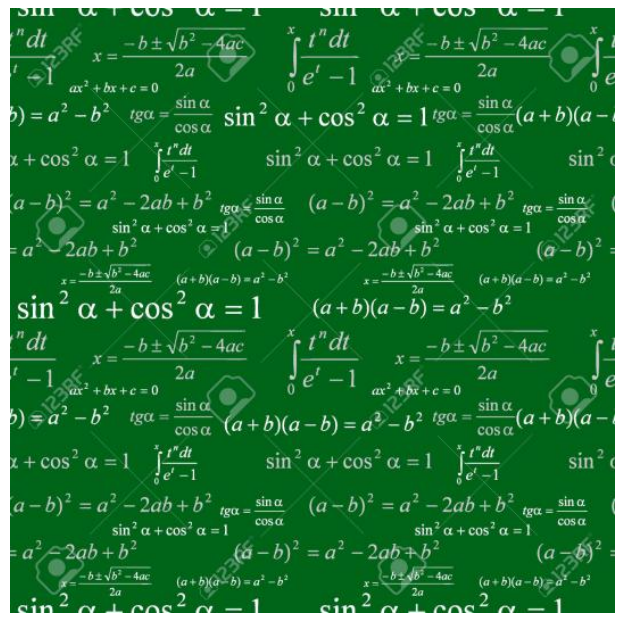

Figure 3: The Symbolic World of Mathematics 


\section{Errors in mathematics}

Addressing students' errors in mathematics is not a new topic in mathematics education. Researchers have looked at the effect of errors on both students and teachers (Gagatsis, \& Kyriakides, 2000; Ingram, Pitt, \& Baldry, 2015; Santagata, 2004; Steuer, Rosentritt-Brunn, \& Dresel, 2013). Others have also looked at the reaction from students and teachers to errors (Bray, 2013; Schleppenbach, Flevares, Sims, \& Perry, 2007). Nevertheless, limited mathematics educators/ researchers explored the type of errors in mathematics classrooms (Guse, 2017). In some cases, the researchers classified the errors in categories based on the essential goals of the study. Here we describe some of these studies:

Guse (2017) explored the writing skills of 12 students in an advanced calculus class. Using a qualitative approach, the researcher classified the errors in students writing in nine categories. The author explained that the most common errors could be one of the following: "misuse of mathematical terms, misuse of mathematical symbols, incorrect notation, incorrect grammar, incorrect capitalization, no or incorrect punctuation, vague term, incorrect term, and lack of term or phrase" (p. 233). The author concluded that teachers and students should commit that it is not only important to solve a problem, but also to be able to articulate the solution in an accurate way.

Naidoo and Naidoo (2007) looked at the effect of using blended learning techniques when teaching elementary calculus to engineering students. The experimental group consisted of 30 students who used software programs along with the traditional teaching approach. The authors concluded that students' errors, although observed to be enormous, can be reduced with blended learning techniques. The authors classified students' errors in three categories. The first category reflects an error in conceptual understanding-Structural Error. The second type occurs when a student fails to carry out a procedure even if he/she understands it-Executive Error. The third type reflects a lack of focus and attention to the writing and the relationship involved among elementsArbitrary Error. Simply a mistake is done because the student "fails to take account of the constraints laid down in what was given" (p. 197). In short, the student is not careful or attentive enough.

Porter and Masingila (1995) explored the effect of writing activities on students' errors in a calculus class. The researchers classified students' errors in three main categories; Conceptual errors, procedural errors and indeterminate. The conceptual errors include the inaccurate choice of a procedure or an algorithm, or the failure to reject an impossible answer. This category also includes the misuse or misinterpretation of a symbol or notation and the inability to use the mathematical answer to interpret the natural phenomena. The second type includes the incomplete or inaccurate writing of symbols or the errors in performing a certain procedure. Moreover, some errors were not categorized in any of the two categories. The researchers suggested that students who experienced the writing activities had less errors than those who did not experience the writing activities. 


\section{Dealing with errors}

Some studies analyzed teachers' reactions to the errors (Gagatsis, \& Kyriakides, 2000; Ingram et al., 2015; Santagata, 2004) while others focused on the effect of errors on students' confidence level and motivation (Steuer et al., 2013). Other researchers advocated for the use of errors to foster students' learning of mathematics (Bray, 2013; Schleppenbach et al., 2007). Ingram et al. (2015) looked at teachers' reactions to errors committed by students in the classrooms rather than those on assessment papers. They used video recording of 22 mathematics classes and the "conversation analytic approach" to classify teachers' responses to errors. Although some teachers tried to use errors as a starting point for a new teaching and learning experience of mathematics, others treated them negatively. The researchers argued that different reactions from teachers creates different opportunities for learning and that teachers should be aware of how to deal with errors in a constructive approach.

On the other hand, Steuer et al. (2013) used data of 1116 students from 56 mathematics classes to classify the effect of error climate in mathematics classrooms. The authors argued that such classification could support teachers to use classroom errors as a new opportunity of learning. On that, other studies focused on classroom discourse after the errors. Schleppenbach et al. (2007) compared how teachers in the US environment reacted to errors vis-a-vis how Chinese teachers did. The researchers-looking at classroom discourse after the error-argued that the US teachers stated the error clearly, while the Chinese teachers tried to ask follow-up questions to point out the error. Moreover, Santagata (2004) also looked at classroom discourse, and how teachers reacted to students' errors. The researcher compared Italian classrooms and US classrooms to conclude that while US teachers try to minimize the effect of the error, Italian teachers repeated the error in a way that aggravated them.

\section{Mathematics language as a universal language}

Although the mathematics language is considered universal for the most part, there are different notations and terms used among scholars in the field. Book authors also use different notations for the same concept. It is common to see several notations for the same concept in one book (Shingareva \& Liza'rragaCelaya, 2015; Pacurar \& Rus, 2018). For example, the differentiation of a function could be written as $\frac{d y}{d x}$ but also as $y$. Moreover, an absolute maximum value of a function could be also called a global maximum or an extreme value. It is important to mention here that book authors prefer to use a specific notation over another depending on several factors such as convenience and the intended audience of the book (Shingareva \& Liza'rraga-Celaya, 2015). However, textbook authors sometimes list all possible notations for a certain concept to give students the overall picture of what they could experience in other textbooks. To add to this, Computer Algebra Systems (CAS) - such as Mathematica or Maple-use different notations. Some CAS notations are not familiar to students. This inevitably will be confusing for students and it will increase the chance of doing mistakes.

Using the correct notation or term is important as it might affect understanding and the meaning of sentences. Shingareva and Liza'rraga-Celaya (2015) argued 
that the use of accurate notation is especially important for mathematics. The author called for a "uniform notational convention" among scholars to avoid confusion. Notably, Pacurar and Rus (2018) stated that the ability to understand different notations is an evidence of proper comprehension of concepts.

\section{Methods}

The study aims to investigate the most common inattentive writing mistakes occurred by students, and to reflect on the ones that could cause serious destruction to the solution. The research questions are the following:

1. What is the most common inattentive error occurred by students?

2. What kind of errors that are the most destructive to the task?

\section{Sampling}

The sample of the study was chosen from one private university in Riyadh, Saudi Arabia. In particular, students' responses in two calculus classes during the two semesters of academic year 2017-2018 were considered.

\section{Data collection}

Data was collected through the following:

1.Written assessments: 250 students' written mathematical assessments (five quizzes and two major exams for each course) have been analysed.

2.Students' work on classrooms' whiteboards were photographed over a period of a month. 30 photographs from the two calculus classes were considered. The photographs were taken only when a student is solving a problem on the board and the response included an inaccurate use of symbols or terms (Figure $4)$.

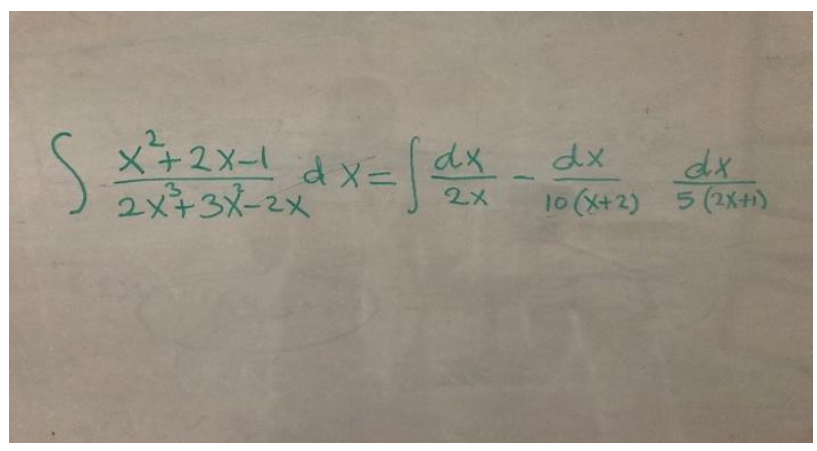

Figure 4: Example of a Response on the Whiteboard

\section{Data analysis}

For written assessments, the analysis was done in two stages.

Stage one: First, the researcher compiled the responses per exam/ quiz. Then, the researcher read through the responses carefully compiling them per question. Meaning, first the researcher read through all responses for question 
one, then for question two and so on. The responses for each question were categorized as the following:

1. Accurate responses, and hence were not considered for analysis;

2. Responses that had inaccurate sections that was due to what appeared to be misunderstanding or a wrong choice of the procedure. The solution was inaccurate. Students might have been given partial credits. However, these assessments were not considered for the study;

3. Responses where the solution or the process was, more or less, accurate but the student committed a careless misuse of the mathematics language, or responses where the solution or the process had an error that is a result of a lack of attention. These were considered for the study. Within this category, the errors were classified into subcategories as the following:

a) Missing a symbol or a notation. (Ex: missing $=,-, \int, d x$, etc.)

b) Misuse of a symbol or a notation (Ex: using $(=)$ to replace $(\Longrightarrow)$ ).

c) Miss-order of operations. (Ex: applying a certain operation on only one side of an equation)

The type of error for each question, for each student, per exam, were coded using a coding system that was developed as represented in Table 1 below.

Table 1: Coding of errors in students' responses

\begin{tabular}{lc}
\hline Type of Error & Code \\
\hline Missing Symbols, Notations & MS \\
\hline Misuse of Symbols, Notations & MU \\
\hline Miss-order of Operations & MO \\
\hline Not applicable; the response is from category 1 or 2 & NA \\
\hline
\end{tabular}

Moreover, the researcher used codes to distinguish students. S1 means the student with serial \# 1.

Stage two: In the second stage, the errors were sorted by type to learn about the repetition of each type of errors in each question and in each exam. For photographed responses from classrooms, the researcher followed the same process. The researcher analyzed each response to be MU, MS, or MO. It is important to mention here that MU and MS, for example, could occur in the same response by a student and hence will be considered for both subcategories. 


\section{The Results}

This study focused on students' errors that occurred in exam papers or classrooms. The study in particular focused on the errors that occurred due to a lack of focus or attention. First, for the exam papers, data was organized and coded per exam, per question, and per student. For example, one quiz (Quiz \# k) in calculus II class had four questions and it was administered on 22 students. The quiz consisted of the following questions:

Find the following integrals:

$Q 1: \int_{0}^{2}(x-1)(2 x+1) d x=$

$Q 2: \int \sqrt{\frac{3}{z}} d z=$

$Q 3: \int_{2}^{5} x \sqrt{x^{2}+5} d x$

Q4: $\int \tan x d x=$

The researcher read through the responses for each student and coded them as shown in Table 2 below.

Table 2: Sample of coding of students' errors in Quiz \# $\mathbf{k}$ in Calculus II

\begin{tabular}{llllll}
\hline Questions & S1 & S2 & S3 & $\ldots \ldots$. & S22 \\
\hline Q1 & NA & MS & NA & $\ldots \ldots$. & MS \\
\hline Q2 & MO & NA & MO/MU & $\ldots \ldots$ & NA \\
\hline
\end{tabular}




\begin{tabular}{llllll}
\hline Q3 & MU & MS & NA & $\ldots$. & MO \\
\hline Q4 & NA & NA & MS & $\ldots \ldots$. & MU \\
\hline
\end{tabular}

Hence, the table shows that response from student 3 to Q2 had MU and MO and to Q4 had MS. Then, the errors were sorted by their type. Using data from Table 2 , the below table (Table 3) shows the frequency of an error for each question. Considering the goal of this research, frequency of the NA category was not calculated

Table 3: Frequencies of types of errors per question in Quiz \# $\mathbf{k}$ in Calculus II

\begin{tabular}{llll}
\hline Questions & MO & MS & MU \\
\hline Q1 & 0 & 10 & 0 \\
\hline Q2 & 0 & 8 & 0 \\
\hline Q3 & & & 2 \\
\hline Q4 & 7 & 2 & 2 \\
\hline Total & 0 & 3 & 1 \\
\hline
\end{tabular}

So, 10 students missed a symbol (a term or a notation) in Q1, but there are seven students committing a miss-order of operation in Q3. In general, there was 23 MS in this quiz verses three MU and seven MO. Table 4 below shows the frequencies of all errors in all assessments (five quizzes and two major exams for each course).

Table 4: Frequencies of all errors in all assessments

\begin{tabular}{llll}
\hline Questions & MO & MS & MU \\
\hline Quiz \# j $(j=1, \ldots 5)$, Calculus I & 25 & 75 & 40 \\
\hline Major \# $\mathrm{m}(m=1,2)$, Calculus I & 2 & 15 & 7 \\
\hline
\end{tabular}




\begin{tabular}{lccc}
\hline Quiz \# $\mathrm{j}(j=1, \ldots 5)$, Calculus II & 35 & 56 & 39 \\
\hline Major \# $\mathrm{m}(m=1,2)$, Calculus II & 8 & 18 & 20 \\
\hline Total & 70 & 164 & 106 \\
\hline
\end{tabular}

For the 30 photographs, the results are represented in Table 5 below.

Table 5: Frequencies of types of errors in 30 photographs over a month

\begin{tabular}{llll}
\hline & MO & MS & MU \\
\hline Calculus I & 2 & 10 & 16 \\
\hline Calculus II & 4 & 6 & 15 \\
\hline
\end{tabular}

Below, I will report on some examples of errors in students' responses that were considered for the analysis.

Example 1: A question from a quiz in calculus I.

The question: Find the derivative of the function $y=3 x^{-6}$. Student's response was

$=18 x^{-7}$

\section{Comments:}

The student did not write the notation $\frac{d y}{d x}$. So, although the student was able to perform the procedure, the way the response is written implies that:

$y=3 x^{-6}=18 x^{-7}$

Such mistake (or similar) occurred repeatedly during quizzes and major exams and also on the whiteboard in classrooms. They looked like of students failed to distinguish between a function and its derivative. Actually, when the student saw the question, she/he wanted to write the derivative and hence the $(=)$ symbol in $\left(=18 x^{-7}\right)$ was treated as (so or then). Moreover, the student missed the notation $\frac{d y}{d x}$. The student should have written:

$\Rightarrow \frac{d y}{d x}=18 x^{-7} \quad$ or 
$\frac{d y}{d x}=18 x^{-7}$

In fact, when this mistake occurred in class, the teacher circled the $(=)$ and asked the student "what equal what?". The student immediately wrote $\frac{d y}{d x}=18 x^{-7}$. This error can be classified as MS.

Example 2: A question from a quiz in calculus I

The question: Express $(\ln b-2 \ln c+2 \ln d)$ as a single logarithm. Student's response is shown in Figure 5.

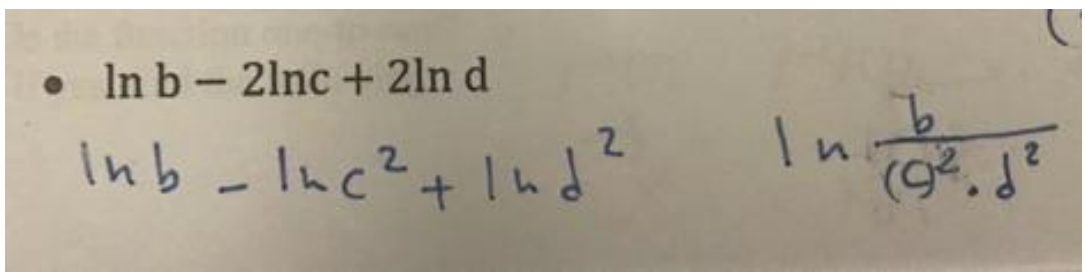

Figure 5: Student's response for question in Example 2

\section{Comments:}

The student missed the $(=)$ between the expressions, although it is clear that she/he knows the properties of the Logarithmic functions. This error could be classified as MS. The student should have written:

$$
\begin{aligned}
& \ln b-2 \ln c+2 \ln d \\
& =\ln b-\ln c^{2}+\ln d^{2} \\
& =\ln \frac{b d^{2}}{c^{2}}
\end{aligned}
$$

Missing symbols could severely affect the solution in other cases. For example, missing brackets/parentheses, can be really damaging to the meaning or can lead to wrong results, as represented in the following example.

Example 3: A question from a quiz in calculus II

The question: Find $\int e^{x} \operatorname{Sin} x d x$. Student's response is shown in Figure 6.

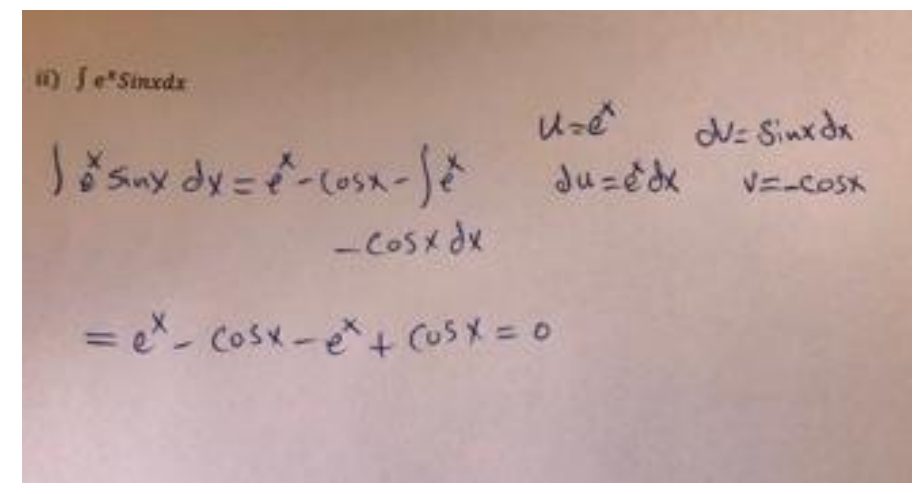

Figure 6: Student's response for question in Example 3 


\section{Comments:}

The student missed the parentheses three times. Hence, the negative sign in $(-\cos x)$ was treated as a substration operation. Instead, the student should have written:

$$
\begin{aligned}
& \int e^{x} \sin x d x=\left(e^{x}\right)(-\cos x)-\int\left[\left(e^{x}\right)(-\cos x)\right] d x \\
& =-e^{x} \cdot \cos x+\int\left[\left(e^{x}\right)(\cos x)\right] d x=-e^{x} \cdot \cos x+\left(e^{x}\right)(\sin x)-\int\left[\left(e^{x}\right)(\sin x)\right] d x \\
& \Rightarrow 2 \int\left[\left(e^{x}\right)(\sin x)\right] d x=-e^{x} \cdot \cos x+\left(e^{x}\right)(\sin x) \\
& \Rightarrow \int\left[\left(e^{x}\right)(\sin x)\right] d x=\frac{1}{2}\left[e^{x}(\sin x-\cos x)\right]+C
\end{aligned}
$$

Example 4: A question from a major exam in calculus I

The question: Find $\frac{d y}{d x}$ of the following function $y=\left(x^{2}+2 x\right)^{\tan x}$. Student's response is shown in Figure 7.

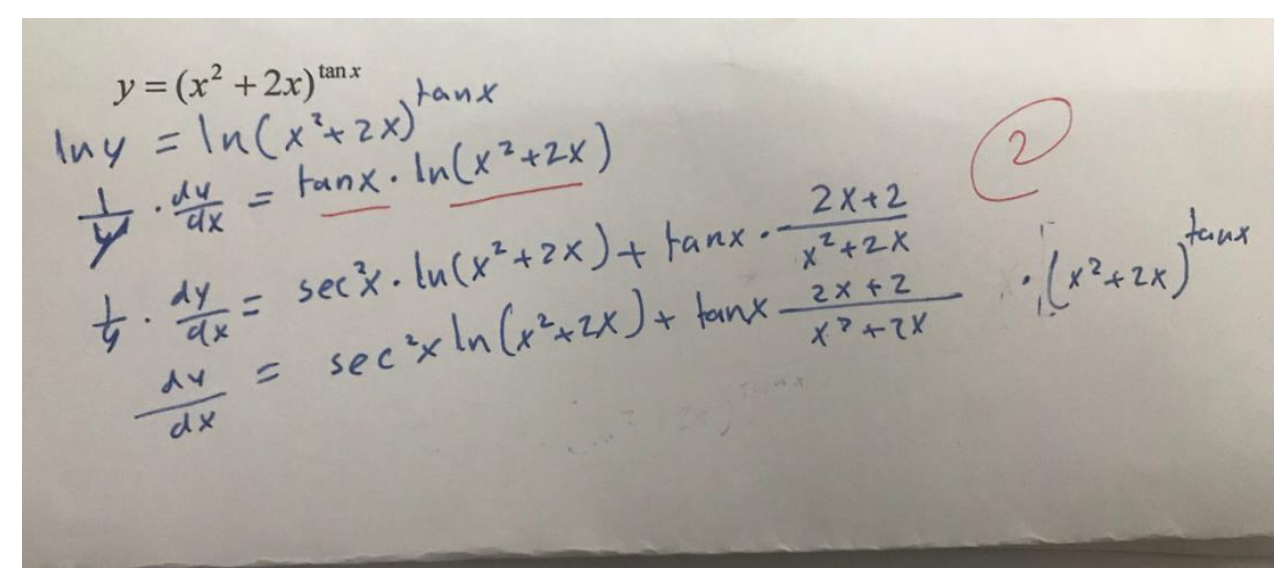

Figure 7: Student's response for question in Example 4

\section{Comments:}

A teacher might ignore the $2^{\text {nd }}$ step and hence, the response deserves a full credit. The issue with the second step is that the student differentiated the left side (using the chain rule) but then when she/he reached the right side, she/he realized that we need to use the logarithmic property to simplify the function to be able to use the product rule. So, she/he differentiated the right side only in the $3^{\text {rd }}$ step. However, this leads to false information in the $2^{\text {nd }}$ step. If step \# 2 is accurate, then:

$\frac{1}{y} \cdot \frac{d y}{d x}=\tan x \cdot \ln \left(x^{2}+2 x\right)$ 
but this means that $\frac{d y}{d x}=\left(x^{2}+2 x\right)^{\tan x}\left[\tan x \cdot \ln \left(x^{2}+2 x\right)\right]$, which is not what we got in (1). Instead, the student should have written:

$\ln y=\ln \left[\left(x^{2}+2 x\right)^{\tan x}\right], \quad$ then

$\ln y=\tan x \cdot \ln \left(x^{2}+2 x\right)$

$\frac{1}{y} \cdot \frac{d y}{d x}=\sec ^{2} x \cdot \ln \left(x^{2}+2 x\right)+\tan x \cdot \frac{2 x+2}{x^{2}+2 x}, \quad \Rightarrow$

$\frac{d y}{d x}=\left(\left(x^{2}+2 x\right)^{\tan x}\right) \cdot\left[\sec ^{2} x \cdot \ln \left(x^{2}+2 x\right)+\tan x \cdot \frac{2 x+2}{x^{2}+2 x}\right]$

The miss-order of applying the operations is more destructive in the following response.

Example 5: A question from a major exam in calculus II

The question: Find the following $\int_{2}^{5} x \sqrt{x^{2}+5} d x$. One response is represented in Figure 8.

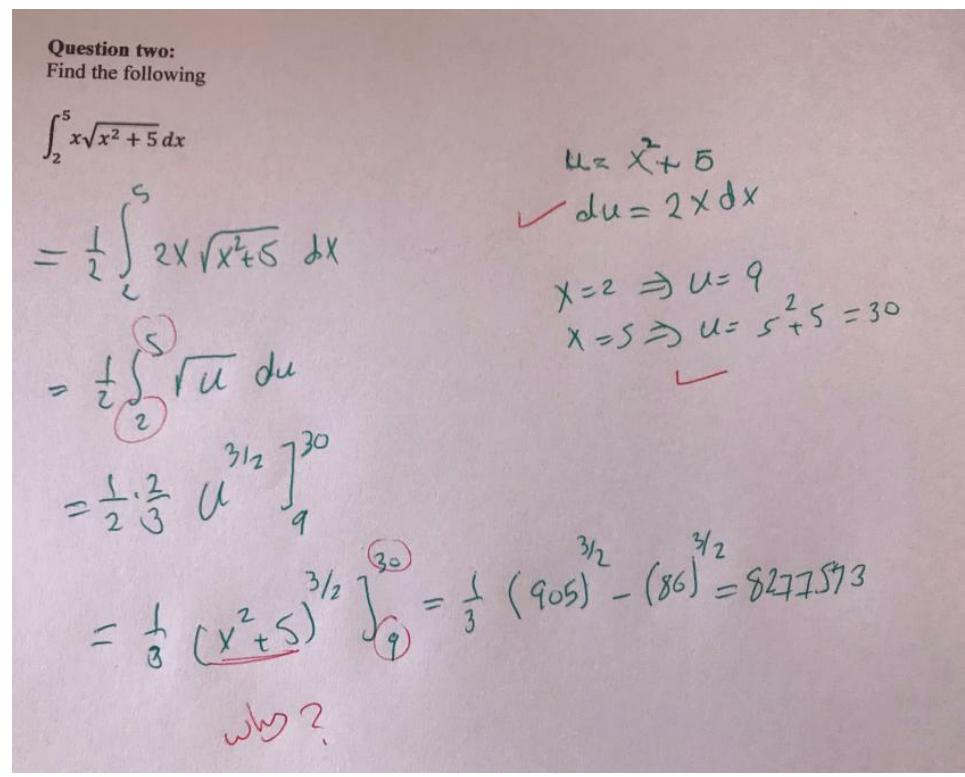

Figure 8: Student's response for question in Example 5

\section{Comments:}

The student committed an error in the $3^{\text {rd }}$ step. Although a substitution was made with $u$ instead of $x$, the limits of the integration were not changed. However, in the $4^{\text {th }}$ step, this mistake was recovered and the limits were changed. Nevertheless, the student did the same mistake in the $5^{\text {th }}$ and $6^{\text {th }}$ steps 
as a re-substitution was made with $x$ instead of $u$ using the upper and lower limits of $u$. In this problem, careless writing resulted in a wrong answer. The student should have done the following:

$\int_{2}^{5} x \sqrt{x^{2}+5} d x$

$=\frac{1}{2} \int_{2}^{5} 2 x \sqrt{x^{2}+5} \mathrm{dx}$, (take $\left.u=x^{2}+5\right)$

$=\frac{1}{2} \int_{9}^{30} \sqrt{u} \mathrm{du}=$

$\left.\frac{1}{2} \cdot \frac{2}{3} \cdot u^{3 / 2}\right]_{9}^{30}$

$=\frac{1}{3}\left[(30)^{3 / 2}-(9)^{3 / 2}\right]=45.77$

An example of the MU is represented in the following response (Figure 9).

Example 6: A question from a quiz in calculus II

Find the following: $\int \frac{x^{2} d x}{\sqrt{4-x^{2}}}$.

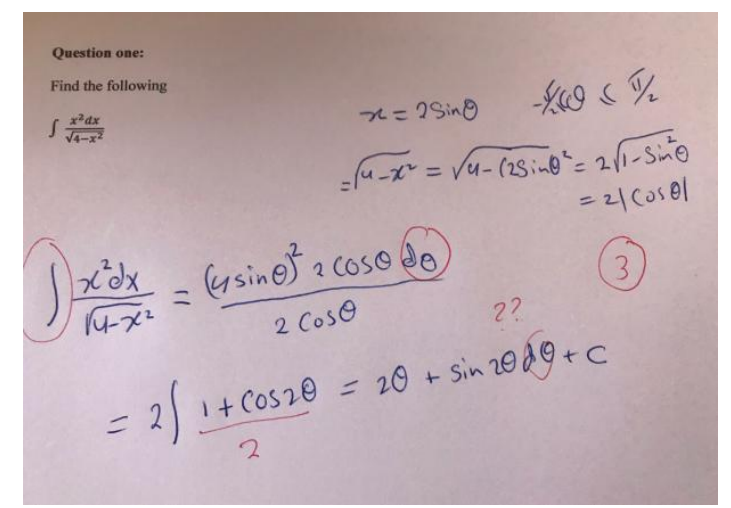

Figure 9: Student's response for question in Example 6

Comments:

The student here committed MU and MS several times. In the $2^{\text {nd }}$ step, there was a misuse of the symbol $(=)$. The student should have used $(\Rightarrow)$ or the word (hence) or only start with the square root symbol. Moreover, the student missed the $\left(\int\right)$ symbol in the $4^{\text {th }}$ step, although $(d \theta)$ was written. In addition, there is an MS and MU of $(d \theta)$ in the $5^{\text {th }}$ and $6^{\text {th }}$ steps respectively. At the end, although the student started with a good choice of trigonometric substitution and was able to perform the integration (more or less), there was too many writing errors. 


\section{Discussion}

From the above analyses, it appeared that the MS and particularly missing the equal sign $(=)$ is the most common error whether in classrooms or in exams. The MU of the $(=)$ and other symbols comes next in repetition. The miss-order of operations appeared to be the most destructive to the overall meaning. It was noticeable that students used the $(=)$ whenever they want to move from one step to another.

Moreover, it appeared that many errors occurred due to students' carelessness. Students are in a hurry to solve a task and are not mindful about their writing. This was evident in the classroom responses. Considering the 30 photographs, the teacher of the class asked follow-up questions pointing out the bad writing. The students were always able to realize and correct the error (see Example 1 above). The use of the follow-up questions technique was reported as an approach used by the Chinese teachers to address classroom errors (Schleppenbach et al., 2007). These follow-up questions, not only supported students to learn from their mistakes by themselves, but they also supported our argument that such errors are not due to lack of comprehensions.

\section{Conclusion}

This study analyzed inattentive errors in students' responses. The results revealed that the extent of repetition of such errors is alarming. This suggests that such errors were not given much attention in previous mathematics classes and unfortunately, these mistakes are becoming habits with students. Ignoring such habits will only lead to more repetition. In fact, we believe that the continuous careless practice of the mathematical language 1) could severely affect the intended meaning and the proposed solution, 2) lead to permanent bad writing habits in classrooms and exams, and 3) represent a lack of professionalism.

Errors in mathematics are expected to happen. Even when Guse (2017) focused on mathematics-major students, the study revealed that students still committed mistakes. This study is not claiming that we should eliminate errors. To the contrary, errors could be used as a starting point for a whole new learning experience (Bray, 2013; Schleppenbach et al., 2007). Nevertheless, it is recommended that teachers address careless writing in mathematics classrooms as early as middle school-when students begin to use abstract mathematics. Teachers are encouraged to emphasize on good writing habits. Students should understand that as much as it is important to know how to apply a certain procedure, it is important to know how to communicate it through accurate writing.

Limitations of the study include the limited sample size and the focus on only calculus classes. It is recommended that future study address mathematics classes at the secondary level and at different classes at the higher education level. It is also advocated to apply a longitudinal study and compare students' writing skills at the secondary level and at the college level. Hearing students' voices through qualitative approach could also inform research on the reasons 
behind such repeatable errors and might also imply approaches for the intervention.

\section{References}

Bray, W. S. (2013). How to leverage the potential of mathematical errors: Incorporating a focus on students' mistakes into your instruction can advance their understanding. Teaching Children Mathematics, 19(7), 425-431. https://doi.org/10.5951/teacchilmath.19.7.0424

Chang, B. L., Cromley, J. G., \& Tran, N. (2016). Coordinating multiple representations in a reform calculus textbook. International Journal of Science and Mathematics Education, 14, 1475-1497. https://doi.org/10.1007/s10763-015-9652-3

Dündar, S. (2016). Does writing have any effect on mathematics success? Journal of Education and Training Studies, 4(1), 1-10. https://doi.org/10.11114/jets.v4i1.989

Freeman, B., Higgins, K. N., \& Horney, M. (2016). How students communicate mathematical ideas: An examination of multimodal writing using digital technologies. Contemporary Educational Technology, 7(4), 281-313. doi: https:// files.eric.ed.gov/fulltext/EJ1117603.pdf

Gagatsis, A., \& Kyriakides, L. (2000). Teachers' attitudes towards their pupils' mathematical errors. Educational Research and Evaluation, 6(1), 24-58. https://doi.org/10.1076/1380-3611(200003)6:1;1-i;ft024

Guse, I. K. (2017). Mathematical writing errors in expository writings of college mathematics students. International Journal of Evaluation and Research in Education, 6(3), 233-242. https://doi.org/10.11591/ijere.v6i3.8549

https://www.researchgate.net/publication/320371742_Mathematical_Writing_Errors_i n_Expository_Writings_of_College_Mathematics_Students

Ingram, J., Pitt, A., \& Baldry, F. (2015). Handling errors as they arise in whole-class interactions. Research in Mathematics Education, 17(3), 183-197. https:// doi.org/10.1080/14794802.2015.1098562

Lee, K. (2010). A guide to writing mathematics. Retrieved on 1 July 2018 from http://web.cs. ucdavis.edu/ amenta/w10/writingman.pdf.

Lo' pez-Gay, R., Sa' ez, M., \& Torregrosa, M. (2015). Obstacles to mathematization in physics: The case of the differential. Science and Education, 24, 591-613. https://doi.org/10.1007/s11191-015-9757-7

McCormick, K. (2010). Experiencing the power of learning mathematics though writing. Undergraduate Mathematics Preparation of School Teachers: The Journal, 4(2), 1-8. doi: https:/ / files.eric.ed.gov/fulltext/EJ914259.pdf.

Naidoo, K., \& Naidoo, R. (2007). Students understanding of the derivative in a blended learning environment: Teaching Calculus in a blended learning environment. The International Journal of Learning, 14(4), 193-202. https://doi.org/10.18848/1447-9494/cgp/v14i04/45279

National Council of Teachers of Mathematics (2000). Principles and standards for school mathematics. Reston, VA: Author.

Pacurar, M., \& Rus, I. A. (2018). Some remarks on the notations and terminology in the ordered set theory. Creative Mathematics and Informatics, 27(2), 191-195. doi: http:// creative-mathematics.ubm.ro/

Porter, M. K, \& Masingila, M. O. (1995). The effect of writing to earn mathematics on the types of errors students make in a college calculus class. Paper presented at the Annual Meeting of the North American Chapter of the International Group for the Psychology of Mathematics Education (17th PME-NA, Columbus, OH, October 2124).

Powell, S. R., \& Hebert, M. A. (2016). Influence of writing ability and computation skill on mathematics writing. The Elementary School Journal, 117(2), 310-335.

https://doi.org/10.1086/688887 
Santagata, R. (2004). Are you joking or are you sleeping? Cultural beliefs and practices in Italian and U.S. teachers' mistake-handling strategies. Linguistic and Education, 15, 41-64. https://doi.org/10.1016/j.linged.2004.12.002

Schleppenbach, M., Flevares, L. M., Sims, L. M., \& Perry, M. (2007). Teachers' responses to student mistakes in Chinese and U.S. mathematics classrooms. The Elementary School Journal, 108(2), 131-147. https://doi.org/10.1086/525551 Actions

Shingareva, I. K., \& Liza' rraga-Celaya, C. (2015). On different symbolic notations for derivatives. The Mathematical Intelligencer, 37(3), 33-38. https://doi.org/10.1007/s00283-014-9526-5

Steuer, G., Rosentritt-Brunn, G., \& Dresel, M. (2013). Dealing with errors in mathematics classrooms: Structure and relevance of perceived error climate. Contemporary Educational Psychology, 38, 196-210. https:// doi.org/10.1016/j.cedpsych.2013.03.002

Urquhart, V. (2009). Using writing in mathematics to deepen student learning. Denver, CO: McREL International. https://files.eric.ed.gov/fulltext/ED544239.pdf

Usiskin, Z. (2012). What does it mean to understand some mathematics? Proceedings of the $12^{\text {th }}$ International Congress on Mathematical Education. Seoul, Korea: ICME. https://doi.org/10.1007/978-3-319-17187-6_46

Veloo, A., Krishnasamy, H. N., \& Wan Abdullah, W. S. (2015). Types of student errors in mathematical symbols, graphs and problem-solving. Asian Social Science, 11(15), 324-334. doi: https://doi.org/10.5539/ass.v11n15p324

Vincent, J., Bardini, C., Pierce, R., \& Pearn, C. (2015). Misuse of the equals sign: An entrenched practice from early primary years to tertiary mathematics. Australian Senior Mathematics Journal, 29(2), 31-39. doi:

https://www.researchgate.net/publication/286418817_Misuse_of_the_equals_s ign_An_entrenched_practice_from_early_primary_years_to_tertiary_mathemati cs. 